\title{
Peningkatan Pemahaman Berhitung dan Kardinalitas melalui Penggunaan Media Rangkasbitung
}

\author{
Eka Nurmala Annisa Rachman ${ }^{{ }_{1}}$, Yetti Supriyati², Yuliani Nurani ${ }^{3}$ \\ Pendidikan Anak Usia Dini, Universitas Negeri Jakarta \\ DOI: $10.31004 /$ obsesi.v4i2.441
}

\begin{abstract}
Abstrak
Penelitian tindakan ini bertujuan untuk menganalisis dan mendeskripsikan aktivitas anak kelompok B TKIT Al Faruqi saat melakukan proses pemahaman berhitung dan kardinalitas melalui penggunaan media Rangkasbitung. Media Rangkasbitung (Barang Bekas Media Berhitung) digunakan sebagai alat untuk menstimulasi kemampuan berhitung dan kardinalitas serta sebagai wujud peningkatan SDM guru dalam berinovasi mengembangkan media pembelajaran. Pendekatan penelitian yang digunakan adalah pendekatan kualitatif dengan desain siklus mengikuti model Kemmis dan McTaggart. Subjek penelitian terdiri dari 15 anak kelompok B TKIT Al Faruqi. Penarikan kesimpulan dilakukan dengan mengubah penilaian kualitatif ke kuantitatif. Analisis data dilakukan dalam tiga tahapan yang terdiri dari reduksi data, penyajian data, dan penarikan kesimpulan. Hasil penelitian menyatakan bahwa aktivitas anak kelompok B TKIT Al Faruqi mengalami peningkatan setelah penerapan kegiatan belajar menggunakan media Rangkasbitung. Melalui data yang dipaparkan dalam penelitian ini dapat diketahui juga bahwa penggunaan media belajar Rangkasbitung mampu meningkatkan kemampuan berhitung dan kardinalitas anak kelompok B TKIT Al Faruqi.
\end{abstract}

Kata Kunci: media pembelajaran; berhitung; kardinalitas; barang bekas

\section{Abstract}

This action research aims to analyze and describe the activities group B of TKIT Al Faruqi students while doing the process of understanding counting and cardinality through the use of Rangkasbitung a.k.a (Used Goods in Counting Media) media, as well as to determine the impact of the use of Rangkasbitung learning media on increasing numeracy skills and cardinality in Group B of TKIT Al Faruqi Sukabumi city. Rangkasbitung a.k.a (Used Goods in Counting Media) is used as a tool to stimulate counting and cardinality skills as well as a form of improvement in teacher human resources in innovating developing learning media. The research approach used is a qualitative approach with a cycle design following the Kemmis and McTaggart models. The research subjects consisted of 15 students from group B TKIT Al Faruqi. Conclusions are drawn by changing qualitative assessments to quantitative. Data analysis is carried out in three stages consisting of data reduction, data presentation, and drawing conclusions. The results of the study stated that the activities of group B TKIT Al Faruqi students increased after the application of learning activities using Rangkasbitung media. Through the data presented in this study it can also be seen that the use of Rangkasbitung learning media is able to improve the numeracy skills and cardinality of group B TKIT Al Faruqi students.

Keywords: learning media; counting; cardinality; used goods

Copyright (c) 2020 Eka Nurmala Annisa Rachman, Yetti Supriyati, Yuliani Nurani

$\triangle$ Corresponding author:

Email Address : ekannisa@gmail.com (Depok, Jawa Barat)

Received 19 January 2020, Accepted 21 January 2020, Published 23 January 2020 


\section{PENDAHULUAN}

Pembangunan karakter bangsa dimulai dari pendidikan anak usia sejak dini. Pendidikan Anak Usia Dini merupakan awal dari sebuah pendidikan untuk menuju cita-cita bangsa sangat memiliki peran yang penting, persaingan global dalam bidang pendidikan saat ini memicu untuk mengembangkan berbagai strategi agar mencapai tujuannya masingmasing. Kondisi tersebut mendorong orangtua untuk dapat menyekolahkan anaknya ke tempat terbaik dengan harapan besar pada lembaga untuk dapat meningkatkan kemampuan akademis anaknya, salah satunya materi matematika seputar pengenalan angka dan proses berhitung, sehingga wacana yang berkembang di masyarakat sebagai orangtua menuntut usia prasekolah untuk dapat segera membaca, menulis dan berhitung, hingga beranggapan bahwa anak cerdas dan pintar merupakan anak yang dapat sedini mungkin mampu membaca menulis dan berhitung melekat pada diri orangtua. Sementara dalam prosesnya kemampuan anak menguasai hal yang disebutkan di atas merupakan bagian yang tidak dapat dipisahkan dari bagaimana lingkungan anak menstimulasi kemampuan kognitif anak. Rosita, (2013) mengemukakan bahwa kemampuan kognitif diperlukan oleh anak dalam rangka mengembangkan pengetahuannya melalui panca indera yang dimiliki. Melalui stimulasi diri dan lingkungan, akhirnya anak mampu membaca, menulis dan berhitung, dengan catatan bahwa semua proses tersebut harus melalui stimulasi di usia yang tepat.

Mempelajari suatu konsep bagi anak bukanlah hal yang mudah, terlebih lagi matematika dalah hal ini konsep berhitung dan kardinalitas. Ismayani, (2010) menyebutkan bahwa ada beberapa faktor yang menyebabkan matematika dianggap pelajaran yang sulit, diantaranya adalah subyek atau pelajaran matematika itu sendiri yang dianggap sulit, metode belajar yang keliru dan membosankan, kurangnya sarana dan prasarana penunjang sehingga membuat anak frustasi dalam mempelajarinya.

Bagi anak belajar bukanlah sesuatu yang harus dilakukan dengan teori ataupun proses belajar formal yang menekankan bisa ini dan itu. Vygotsky menyatakan bahwa proses belajar pada anak merupakan proses berkelanjutan yang harus memiliki rangkaian kesatuan antara anak dengan orang dewasa agar anak mampu memecahkan masalah secara mandiri melalui pengalaman yang mereka alami dengan teman sebayanya dan hal tersebut dikenal sebagai Zona Proximal Development (ZPD) pada teori perkembangan sosial kognitif. ZPD adalah istilah Vygotsky untuk tugas-tugas yang terlalu sulit dikuasai sendiri oleh anak, tetapi dapat dikuasai dengan bimbingan dan bantuan dari orang-orang dewasa atau anakanak yang lebih terampil (Nurani, 2019).

Kompleksitas anak usia dini dalam mempelajari berhitung dam kardinalitas ini tentu saja tidak terlepas dari bagaimana proses dan keluasan pengalamannya dalam memahami suatu konsep. Erlina, (2018) mengemukakan bahwa pemahaman anak terhadap konsep matematika terjadi dalam tiga tahapan yaitu; 1) Pemahaman Konsep (intuitive concept level), pada tahap ini anak memahami berbagai konsep matematika melalui pegalaman bekerja dan bermain dengan benda-benda konkrit. Kemudian, setelah anak memahami konsep guru mengenalkan lambang konsep; 2) Masa transisi (connecting level), pada tahap ini anak sedang dalam proses asimilasi dan akomodasi; 3) Tingkat lambang bilangan (symbolic level), pada tahap ini guru baru dapat mengenalkan berbagai lambang bilangan yang ada dalam matematika sebagai penyempurna proses kognitif anak.

Pixner, Dresen, \& Moeller (2018) menyatakan bahwa anak usia 4 hingga 5 tahun memiliki pemahaman tentang angka kecil dan nol serta visuospasial, bahasa umum, penghitungan, kemampuan identifikasi angka Arab, dan pengetahuan jumlah jari. Kemampuan menghitung dan memahami kardinalitas adalah langkah penting dalam perkembangan numerik anak-anak. Hasil penelitian memperkuat pengaruh kemampuan berhitung pada pengetahuan tentang nol dan pengaruh kemampuan berhitung dan pengetahuan jari pada pemahaman anak-anak tentang kardinalitas angka kecil. Tidak ada pengaruh signifikan dari prediktor lintas domain yang diamati. Singkatnya, hasil tersebut menunjukkan bahwa keterampilan prekursor numerik spesifik-domain tampaknya lebih 
penting untuk pengembangan anak-anak pada pemahaman kardinalitas angka kecil serta konsep nol daripada kemampuan lintas-domain yang lebih proksimal seperti kemampuan bahasa dan kemampuan visuospasial.

Menurut Boggan, Harper, \& Whitmire, (2010) penting bagi anak-anak untuk memiliki berbagai bahan untuk dimanipulasi dan kesempatan untuk menyortir, mengklasifikasikan, menimbang, menumpuk, dan mengeksplorasi jika mereka ingin membangun pengetahuan matematika. Selain itu disebutkan bahwa sumber daya materi dapat digunakan di kelas mana saja untuk memperkenalkan, mempraktikkan, atau bahkan memulihkan konsep matematika

Berdasarkan pemaparan yang dikemukakan, maka untuk menjembatani kesenjangan cara pembelajaran matematika khususnya berhitung dan kardinalitas serta segala tuntutan serta harapan orangtua, para pendidik anak usia dini harus fokus untuk mempertahankan pembelajaran yang berpusat pada anak, bukan dengan memaksakan penerapan matematika yang seringkali menggunakan lembar kerja untuk pencapaiannya tanpa memperhatikan proses. Pelaksanaan kajian ilmu mengenai matematika ini sangat luas, adapun fokus dari penelitian ini adalah kemampuan berhitung dan kardinalitas (himpunan) pada anak usia dini menggunakan media Rangkasbitung (Barang Bekas Media Berhitung). Guru yang memiliki kreativitas tinggi dapat memanfaatkan bahan-bahan sederhana di sekitarnya untuk menciptakan media pembelajaran yang sesuai dengan kebutuhan kegiatan belajar mengajar di kelasnya (Siarni dan Pasaribu, 2015). Dalam lingkungan lembaga pendidikan, pengadaan media pembelajaran terkadang tidak sesuai dengan kebutuhan proses pembelajaran berlangsung dan banyak mengandalkan barang beli jadi atau habis pakai. Rangkasbitung (Barang Bekas Media Berhitung) dibuat sebagai salah satu upaya meningkatkan kemampuan anak dalam memahami konsep berhitung yang dilatar belakangi kondisi empirik yang terjadi di taman kanak-kanak saat ini, sekaligus sebagai upaya untuk meningkatkan kecintaan kita terhadap lingkungan melalui pemanfaatan barang-barang bekas sebagai media pembelajaran dengan menekankan prinsip $3 \mathrm{R}$ yaitu Reduce (mengurangi), Reuse (Pemakaian Kembali) dan Recycle (Daur Ulang).

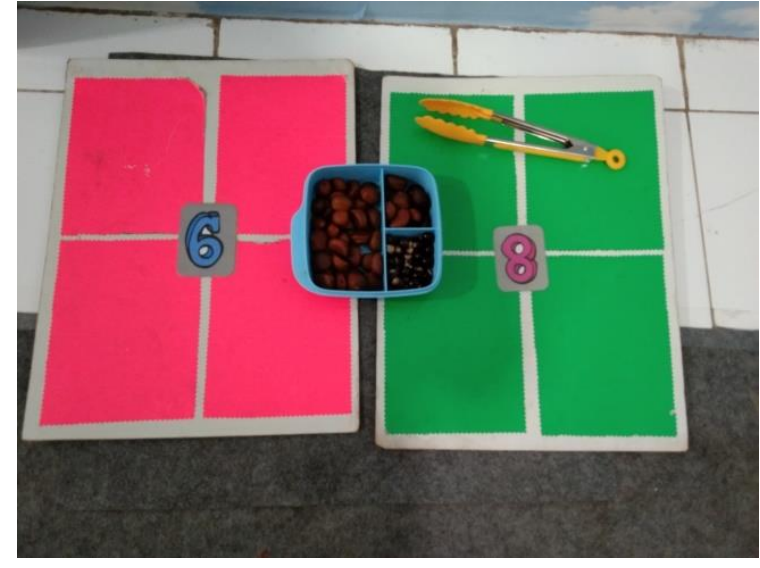

Gambar 2.1 Media Papan Konsep Rangkasbitung

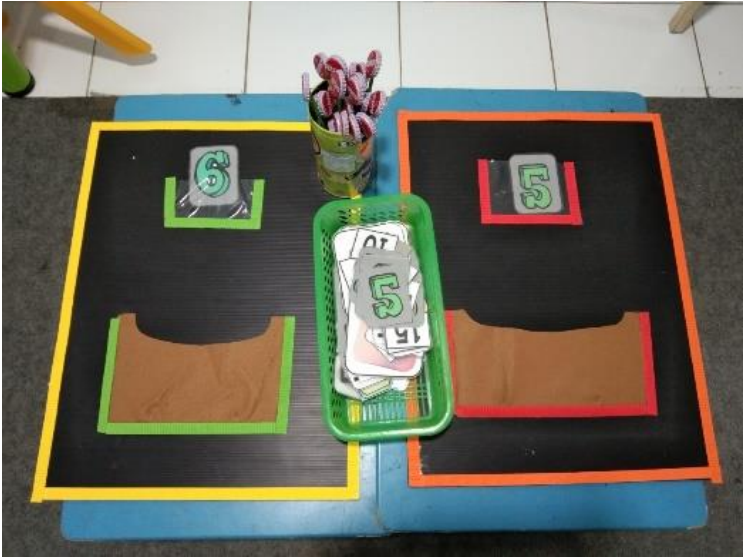

Gambar 2.2 Media Papan Alas Cropstick Rangkasbitung 


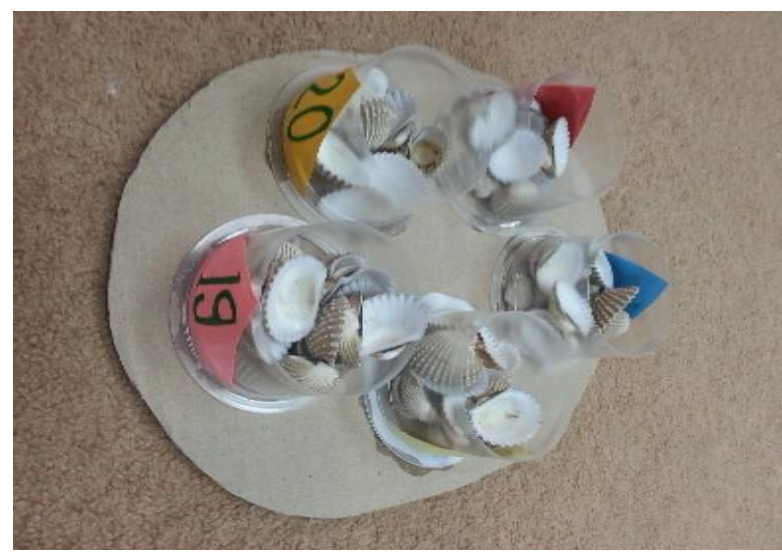

Gambar 2.3 Media Glastik Rangkasbitung

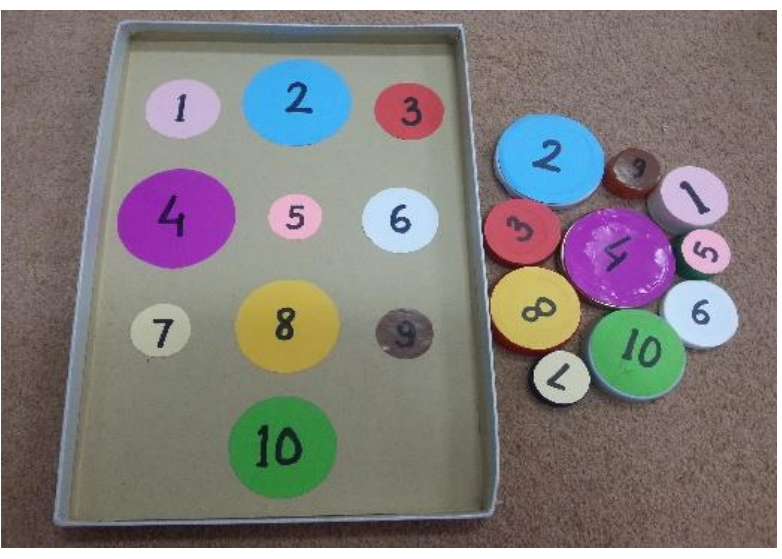

Gambar 2.4 Media Pancok Aneka Tutup Rangkasbitung

\section{METODOLOGI}

Penelitian ini merupakan Penelitian Tindakan Kelas (classroom action research) yang menggunakan metode campuran (mixing method) dengan pendekatan kualitatif dan kuantitatif. Setiawan, (2015) mengemukakan bahwa penelitian tindakan kelas adalah penelitian yang dilaksanakan oleh guru terhadap dirinya dan siswa-siswa yang diajarnya di kelas tertentu dengan tujuan untuk memperbaiki proses dan meningkatkan hasil pembelajaran. Selain itu Arikunto, (2008) menyebutkan bahwa penelitian tindakan merupakan suatu pencermatan terhadap kegiatan belajar, berupa sebuah tindakan yang sengaja dimunculkan dan terjadi dalam sebuah kelas secara bersama.

Penelitian kualitatif itu dilakukan secara intensif, peneliti ikut berpartisipasi lama di lapangan, mencatat secara hati-hati apa yang terjadi, melakukan analisis reflektif terhadap berbagai dokumen yang ditemukan di lapangan, dan membuat laporan penelitian secara mendetail (Sugiyono, 2008). Penelitian ini dilaksanakan pada semester 2 kegiatan belajar mengajar di taman kanak-kanak. Adapun tempat penelitian yang digunakan dalam penelitian ini adalah TKIT Al Faruqi yang beralamat di Jl. Selabintana No 23 Kota Sukabumi. Penelitian Tindakan Kelas ini dilakukan pada siswa kelompok B TKIT Al Faruqi Kota Sukabumi sebanyak 15 siswa, yang terdiri dari 8 siswa perempuan dan 7 siswa laki-laki pada tahun pelajaran 2019-2020.

Agar penelitian ini berhasil dan menjadikan pembelajaran lebih baik dari sebelumnya maka peneliti perlu mengetahui karaktersistik penting dalam PTK menurut (Muslihuddin, 2014) yaitu, 1) Didasarkan pada masalah yang dihadapi guru dalam instruksional; 2) Adanya kolaborasi dalam pelaksanaanya; 3) Peneliti sekaligus sebagai praktisi yang melakukan refleksi; 4) Bertujuan memperbaiki atau meningkatkan kualitas praktek instruksional; 5) Dilaksanakan dalam rangkaian langkah dengan beberapa siklus.

Untuk menggambarkan secara umum bagaimana penelitian tindakan ini dilaksanakan berikut merupakan gambaran proses pelaksanaan tindakan untuk meningkatkan kemampuan memahami konsep bilangan dan kardinalitas menggunakan media Rangkasbitung : 


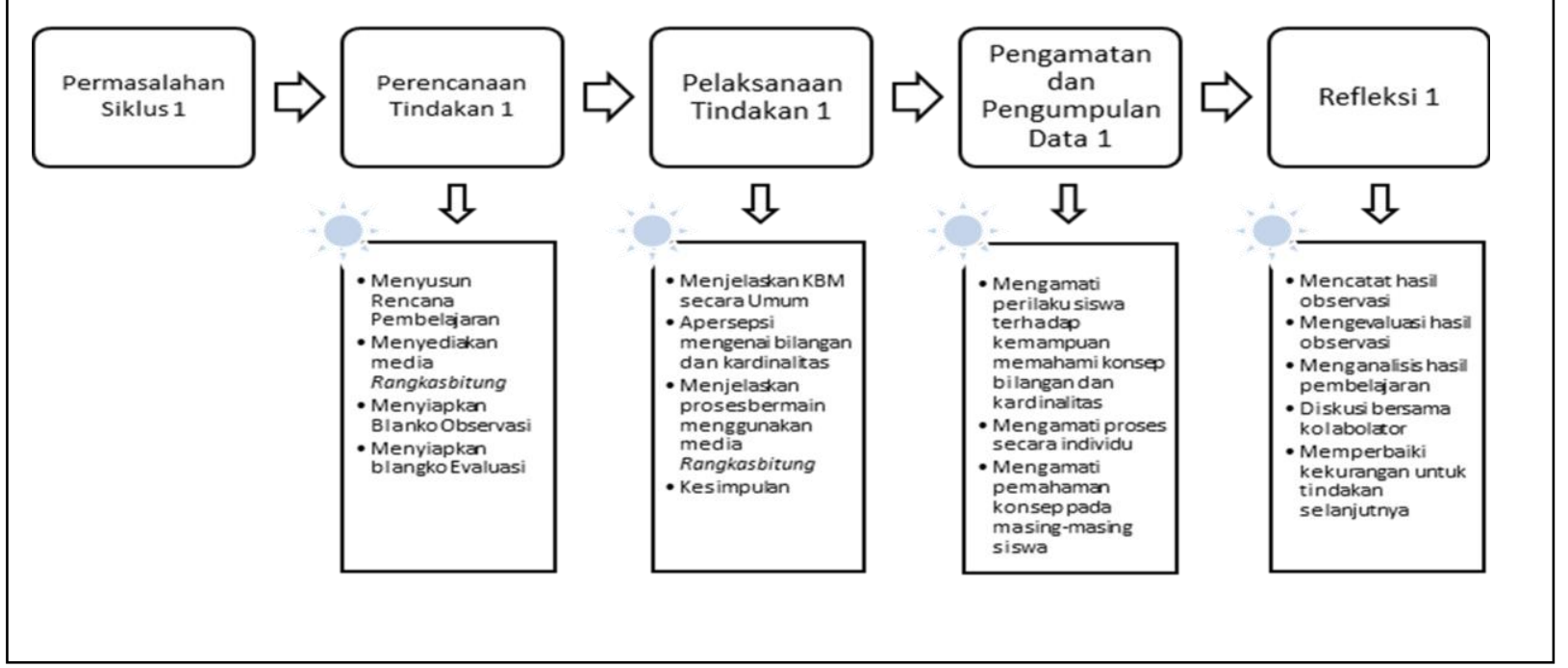

Gambar 2.1 Siklus Tindakan 1

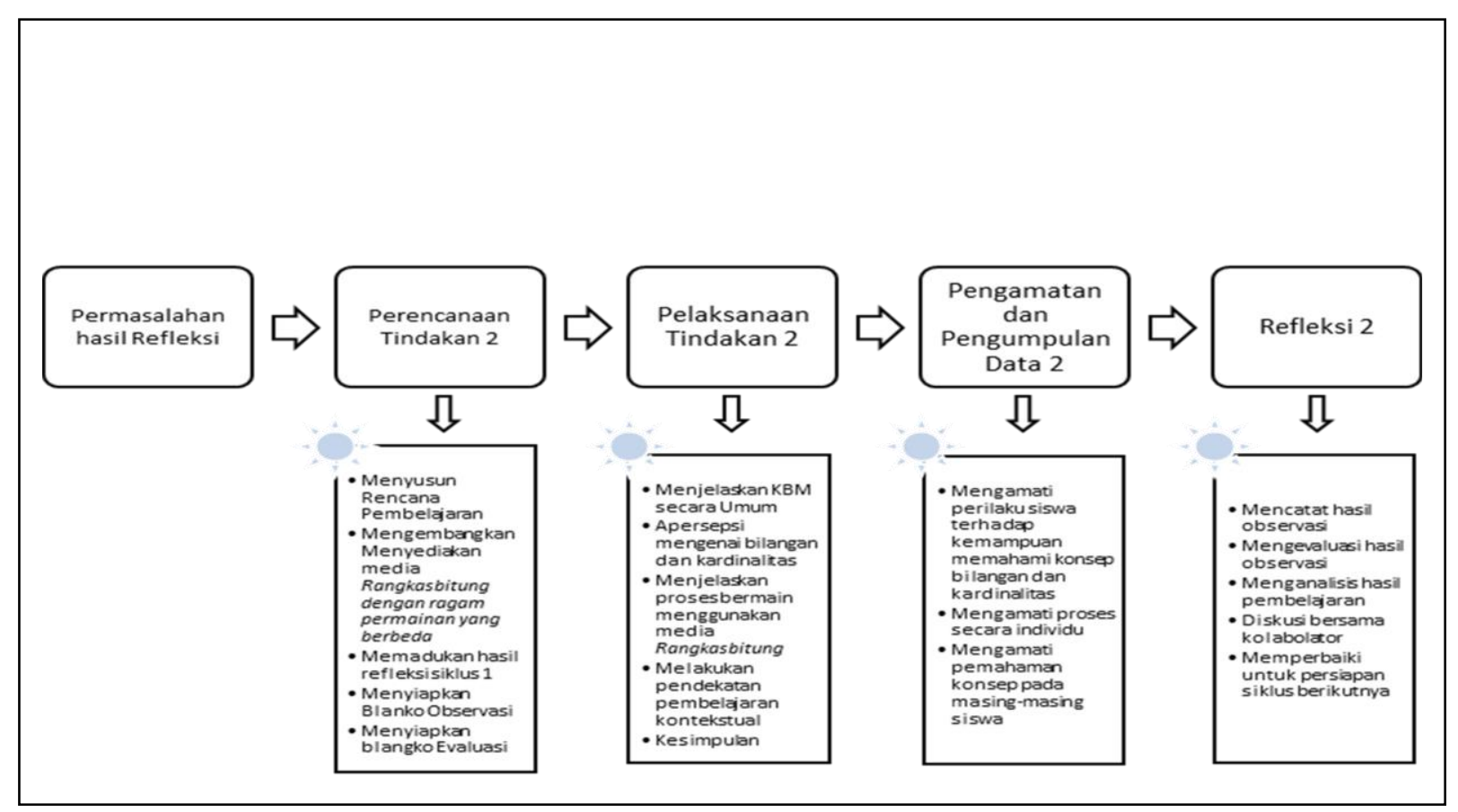

Gambar 2.2 Siklus Tindakan

Instrumen yang digunakan dalam penelitian ini menggunakan skala. Rating-scale digunakan untuk mengolah data berupa angka untuk menilai peningkatan pemahaman anak dalam berhitung dan kardinalitas. Instrumen penilaian berisi item kemampuan memahami konsep berhitung dan kardinalitas untuk anak usia dini dengan kisi-kisi sebagai berikut : 
DOI: $10.31004 /$ obsesi.v4i2.441

Tabel 2.1 Kisi-kisi Instrumen Kemampuan Memahami Konsep Berhitung dan Kardinalitas

\begin{tabular}{l|l|c|c}
\hline \multicolumn{1}{c|}{ Aspek } & \multicolumn{1}{c|}{ Indikator } & $\begin{array}{c}\text { No } \\
\text { Butir }\end{array}$ & Jumlah \\
\hline \multirow{2}{*}{ Berhitung } & $\begin{array}{l}\text { Mengetahui nama Angka } \\
\text { dan Urutan Angka }\end{array}$ & $1,2,3$ & 3 \\
\cline { 2 - 4 } & Membandingkan Angka & 4,5 & 2 \\
\hline $\begin{array}{l}\text { Kardinalitas } \\
\text { (jumlah elemen dalam satu set } \\
\begin{array}{l}\text { atau pengelompokan lainnya, } \\
\text { sebagai properti dari } \\
\text { pengelompokan tersebut.) }\end{array}\end{array}$ & $\begin{array}{l}\text { Menghitung untuk } \\
\text { mengetahui banyaknya } \\
\text { objek }\end{array}$ & $\begin{array}{c}6,7,8,9, \\
10\end{array}$ & 5 \\
\hline
\end{tabular}

Penyajian data dalam penelitian ini secara umum akan ditampilkan dalam bentuk deskriptif dimana proses penyajian data berdasarkan laporan naratif untuk menyajikan gambaran lengkap proses penelitian hingga proses penarikan kesimpulan dengan mengubah Penilaian Kualitatif ke Dalam Penilaian Kuantitatif :

Tabel 2.2 Skala Penilaian Aktivitas Siswa

\begin{tabular}{clc}
\hline Skala & \multicolumn{1}{c}{ Keterangan } & Skor (\%) \\
\hline $\mathbf{1}$ & Sangat Kurang & $10-29$ \\
\hline $\mathbf{2}$ & Kurang & $29-50$ \\
\hline $\mathbf{3}$ & Cukup & $50-69$ \\
\hline $\mathbf{4}$ & Baik & $70-89$ \\
\hline $\mathbf{5}$ & Sangat Baik & $90-100$ \\
\hline
\end{tabular}

Tabel 2.3 Skala Penilaian Kemampuan Berhitung dan Kardinalitas

\begin{tabular}{clc}
\hline Skala & \multicolumn{1}{c}{ Keterangan } & Skor $(\mathbf{\%})$ \\
\hline $\mathbf{1}$ & Belum Berkembang & $<20$ \\
\hline $\mathbf{2}$ & Mulai Berkembang & $20-59$ \\
\hline $\mathbf{3}$ & Berkembang Sesuai Harapan & $60-79$ \\
\hline $\mathbf{4}$ & Berkembang Sangat baik & $80-100$ \\
\hline
\end{tabular}

Tingkat capaian perkembangan minimal (TCP) yang ditetapkan oelh peneliti dan kolabolator berdasarkan kategori skala kemampuan berhitung dan kardinalitas yang ditentukan adalah ketika kemampuan anak sudah mencapai kategori minimal Berkembang Sesuai Harapan (BSH) yaitu 60-79\%.

\section{HASIL DAN PEMBAHASAN}

Hasil penelitian menunjukkan bahwa peningkatan berhitung dan kardinalitas anak kelompok B TK Islam Terpadu Kota Sukabumi meningkat. Berikut merupakan data hasil perbandingan kemampuan berhitung dan kardinalitas melalui media Rangkasbitung mulai dari pra tindakan, siklus I dan siklus II.

\section{Pra Siklus}

Hasil pra siklus menunjukkan bahwa rata-rata skor keseluruhan siswa kelompok B adalah 23,73 atau 59\% dari skor maksimal, sehingga termasuk ke dalam kategori Mulai Berkembang (MB). Adapun secara individual, terdapat enam anak yang berada pada kategori Mulai Berkembang (MB), sedangkan sisanya, yaitu 9 anak termasuk ke dalam kategori Berkembang Sesuai Harapan (BSH). 
DOI: 10.31004/obsesi.v4i2.441

Siklus I

Selama pelaksanaan kegiatan pembelajaran menggunakan media Rangkasbitung pada siklus 1, peneliti melakukan observasi terhadap aktivitas anak pada setiap tahapan dalam siklus 1 . Berikut ini skor dan kriteria keaktifan tiap anak yang dinilai oleh peneliti berdasarkan observasi terhadap aktivitas anak selama siklus 1:

Tabel 3.1 Aktivitas siswa menggunakan media Rangkasbitung pada siklus I

\begin{tabular}{ccccc}
\hline No & Nama & Skor & Persentase & Kategori \\
\hline $\mathbf{1}$ & Al & 16 & $46 \%$ & Kurang \\
\hline $\mathbf{2}$ & Fa & 12 & $34 \%$ & Kurang \\
\hline $\mathbf{3}$ & Fir & 12 & $34 \%$ & Kurang \\
\hline $\mathbf{4}$ & Gif & 14 & $40 \%$ & Kurang \\
\hline $\mathbf{5}$ & Kei & 13 & $37 \%$ & Kurang \\
\hline $\mathbf{6}$ & Li & 10 & $29 \%$ & Sangat Kurang \\
\hline $\mathbf{7}$ & So & 12 & $34 \%$ & Kurang \\
\hline $\mathbf{8}$ & Faj & 13 & $37 \%$ & Kurang \\
\hline $\mathbf{9}$ & Nau & 13 & $37 \%$ & Kurang \\
\hline $\mathbf{1 0}$ & Ov & 11 & $31 \%$ & Kurang \\
\hline $\mathbf{1 1}$ & Iv & 12 & $34 \%$ & Kurang \\
\hline $\mathbf{1 2}$ & Na & 15 & $43 \%$ & Kurang \\
\hline $\mathbf{1 3}$ & Nah & 14 & $40 \%$ & Kurang \\
\hline $\mathbf{1 4}$ & Naz & 10 & $29 \%$ & Sangat Kurang \\
\hline $\mathbf{1 5}$ & Nay & 10 & $29 \%$ & Sangat Kurang \\
\hline \multicolumn{2}{c}{ Rata-Rata } & 12,5 & $36 \%$ & Kurang \\
\hline
\end{tabular}

Data pada tabel di atas menunjukkan bahwa dari 15 siswa terdapat 3 siswa yang tingkat keaktifannya berada pada kategori sangat kurang, sedangkan 12 siswa lainnya termasuk kategori kurang aktif. Secara keseluruhan, rata-rata tingkat keaktifan 15 siswa kelompok B TKIT Al Faruqiberada pada kategori kurang. Hasil ini juga menunjukkan bahwa rata-rata siswa masih belum memfokuskan keseluruhan aktivitasnya pada kegiatan pembelajaran pada siklus 1 dan masih disibukkan oleh aktivitas-aktivitas lainnya di luar konteks kegiatan pembelajaran menggunakan media Rangkasbitung.

Hasil siklus I menunjukkan bahwa dari 15 siswa kelompok B TKIT Al Faruqi yang telah melalui kegiatan pembelajaran menggunakan media Rangkasbitung pada siklus 1, terdapat 3 anak yang yang berada pada kategori Berkembang Sangat Baik (BSB), 10 anak termasuk kategori Berkembang Sesuai Harapan (BSH), dan 2 anak termasuk kategori Mulai Berkembang (MB). Secara keseluruhan, rata-rata kemampuan berhitung dan kardinalitas dari 15 siswa kelompok B TKIT Al Faruqi berada pada kategori Berkembang Sesuai Harapan (BSH).

\section{Siklus II}

Melalui hasil refleksi dan evaluasi, ragam permainan rangkasbitung diperbanyak dengan maksud agar anak-anak lebih tertarik untuk melakukan kegiatan dengan variasi alat, bahan dan jenis main yang berbeda. Peningkatan aktivitas siswa menggunakan media rangkasbitung menunjukkan peningkatan yang tersaji pada table berikut ini : 
Tabel 3.2 Aktivitas siswa menggunakan media Rangkasbitung pada siklus II

\begin{tabular}{ccccc}
\hline No & Nama & Skor & Persentase & Kategori \\
\hline $\mathbf{1}$ & Al & 24 & $69 \%$ & Cukup \\
\hline $\mathbf{2}$ & Fa & 26 & $74 \%$ & Baik \\
\hline $\mathbf{3}$ & Fir & 23 & $66 \%$ & Cukup \\
\hline $\mathbf{4}$ & Gif & 25 & $71 \%$ & Baik \\
\hline $\mathbf{5}$ & Kei & 29 & $83 \%$ & Baik \\
\hline $\mathbf{6}$ & Li & 26 & $74 \%$ & Baik \\
\hline $\mathbf{7}$ & So & 26 & $74 \%$ & Baik \\
\hline $\mathbf{8}$ & Faj & 26 & $74 \%$ & Baik \\
\hline $\mathbf{9}$ & Nau & 27 & $77 \%$ & Baik \\
\hline $\mathbf{1 0}$ & Ov & 24 & $69 \%$ & Cukup \\
\hline $\mathbf{1 1}$ & Iv & 25 & $71 \%$ & Baik \\
\hline $\mathbf{1 2}$ & Na & 25 & $71 \%$ & Baik \\
\hline $\mathbf{1 3}$ & Nah & 27 & $77 \%$ & Baik \\
\hline $\mathbf{1 4}$ & Naz & 25 & $71 \%$ & Baik \\
\hline $\mathbf{1 5}$ & Nay & 24 & $69 \%$ & Cukup \\
\hline \multicolumn{2}{c}{ Rata-Rata } & 25,5 & $73 \%$ & Baik \\
\hline
\end{tabular}

Data pada tabel di atas menunjukkan bahwa dari 15 siswa terdapat 4 siswa yang tingkat keaktifannya berada pada kategori cukup, sedangkan keaktifan 11 siswa lainnya termasuk kategori baik. Secara keseluruhan, rata-rata tingkat keaktifan 15 siswa kelompok B TKIT Al Faruqiselama pelaksanaan kegiatan pembelajaran menggunakan media rangkasbitung pada siklus berada pada kategori baik.

Setelah melalui proses refleksi dan evaluasi, kemampuan berhitung dan kardinalitas pada siklus II menunjukkan bahwa 15 siswa kelompok B TKIT Al Faruqi yang telah melalui kegiatan pembelajaran menggunakan media Rangkasbitung pada siklus 2 mampu mencapai kategori Berkembang Sangat Baik dalam hal kemampuan berhitung dan kardinalitasnya. Secara keseluruhan, rata-rata kemampuan berhitung dan kardinalitas dari 15 siswa kelompok B TKIT Al Faruqi berada pada kategori Berkembang Sangat Baik (BSB). Berikut merupakan perbandingan peningkatan kemampuan berhitung dan kardinalitas mulai dari pra siklus hingga siklus II :

Tabel 3.3 Perbandingan Kemampuan Berhitung dan Kardinalitas Pra-Siklus, Siklus 1 dan Siklus 2

\begin{tabular}{cccccccc}
\hline \multirow{2}{*}{ No } & \multirow{2}{*}{ Nama } & \multicolumn{2}{c}{ Pra-Siklus } & \multicolumn{2}{c}{ Siklus 1 } & \multicolumn{2}{c}{ Siklus 2 } \\
\cline { 3 - 8 } & & Skor & Kategori & Skor & Kategori & Skor & Kategori \\
\hline $\mathbf{1}$ & Al & 24 & BSH & 32 & BSB & 35 & BSB \\
\hline $\mathbf{2}$ & Fa & 21 & MB & 23 & MB & 32 & BSB \\
\hline $\mathbf{3}$ & Fir & 22 & MB & 28 & BSH & 33 & BSB \\
\hline $\mathbf{4}$ & Gif & 22 & MB & 35 & BSB & 36 & BSB \\
\hline $\mathbf{5}$ & Kei & 24 & BSH & 29 & BSH & 32 & BSB \\
\hline $\mathbf{6}$ & Li & 24 & BSH & 24 & BSH & 32 & BSB \\
\hline $\mathbf{7}$ & So & 22 & MB & 23 & MB & 32 & BSB \\
\hline $\mathbf{8}$ & Faj & 28 & BSH & 29 & BSH & 32 & BSB \\
\hline $\mathbf{9}$ & Nau & 28 & BSH & 30 & BSH & 33 & BSB \\
\hline $\mathbf{1 0}$ & Ov & 20 & MB & 27 & BSH & 33 & BSB \\
\hline $\mathbf{1 1}$ & Iv & 24 & BSH & 30 & BSH & 34 & BSB \\
\hline $\mathbf{1 2}$ & Na & 25 & BSH & 35 & BSB & 36 & BSB \\
\hline $\mathbf{1 3}$ & Nah & 23 & MB & 28 & BSH & 32 & BSB \\
\hline $\mathbf{1 4}$ & Naz & 24 & BSH & 26 & BSH & 33 & BSB \\
\hline $\mathbf{1 5}$ & Nay & 25 & BSH & 29 & BSH & 36 & BSB \\
\hline Rata-Rata & 23,73 & MB & 28,53 & BSH & 33,4 & BSB \\
\hline
\end{tabular}


DOI: 10.31004/obsesi.v4i2.441

Data di atas menunjukkan peningkatan yang berkelanjutan dalam kemampuan berhitung dan kardinalitas siswa TKIT Al Faruqi antara pra-siklus, siklus 1, dan siklus 2 . Rata-rata kemampuan berhitung dan kardinalitas siswa pada pra-siklus adalah 23,73 dengan kategori Mulai Berkembang (MB) meningkat menjadi 28,53 dengan kategori Berkembang Sesuai Harapan (BSH) pada siklus 1, dan terakhir kembali meningkat menjadi seebsar 33,4 dengan kategori Berkembang Sangat Baik (BSB) pada siklus 2.

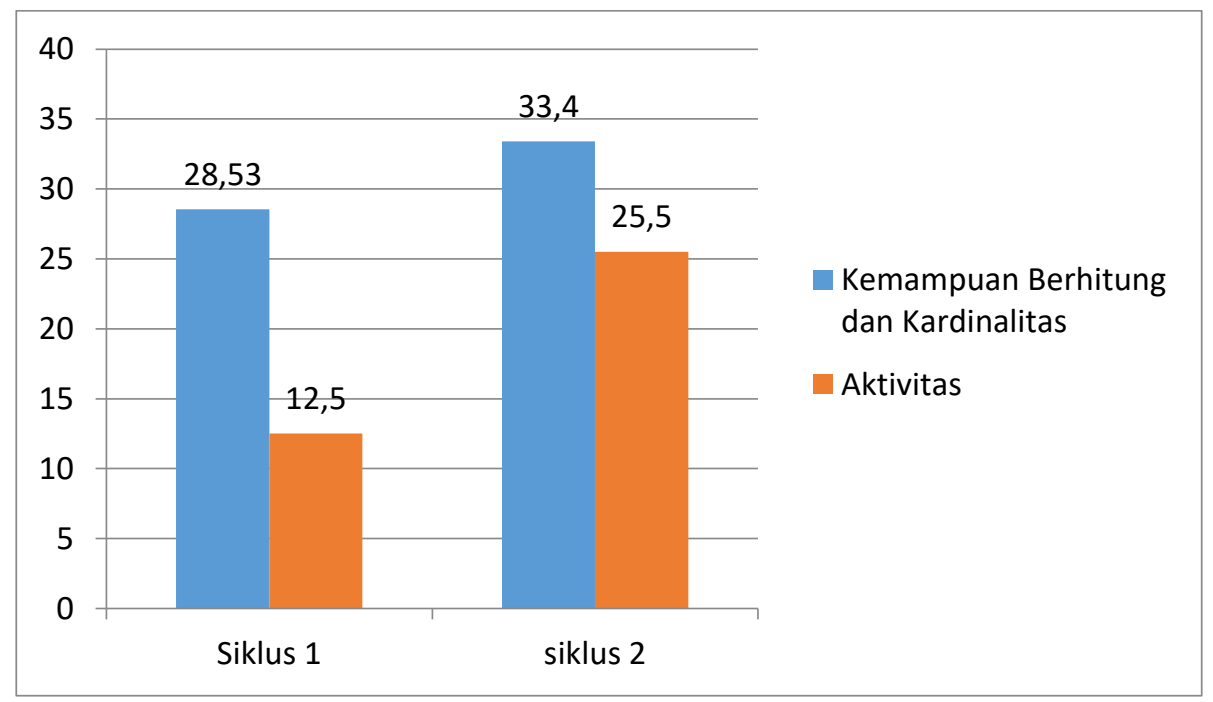

Gambar 3.1. Hubungan antara Aktivitas dan Kemampuan Berhitung dan Kardinalitas Siswa

Gambar di atas menunjukkan bahwa penggunaan media belajar rangkasbitung mampu meningkatkan aktivitas siswa dari siklus 1 dengan skor rata-rata 12,5 dan termasuk kategori kurang meningkat menjadi 25,5 dengan kategori baik pada siklus 2 . Hal tersebut dapat diartikan bahwa anak menjadi lebih aktif dalam mengikuti setiap proses melaksanakan kegiatan pembelajaran menggunakan media rangkasbitung, mulai dari tahap persiapan, tahap pembukaan, tahap pelaksanaan pembelajaran, hingga tahap penutup.

Hasil analisis menunjukkan bahwa kegiatan pembelajaran menggunakan media rangkasbitung, baik pada siklus 1 maupun siklus 2, telah berhasil meningkatkan kemampuan berhitung dan kardinalitas siswa kelompok B TKIT Al-Faruqi. Hal ini terlihat pada peningkatan pada skor rata-rata dan kategori kemampuan siswa, yaitu dari 23,73 dengan kategori Mulai Berkembang (MB) meningkat menjadi 28,53 dengan kategori Berkembang Sesuai Harapan (BSH) pada siklus 1, dan terakhir kembali meningkat menjadi sebesar 33,4 dengan kategori Berkembang Sangat Baik (BSB) pada siklus 2. Hasil ini sejalan dengan temuan penelitian oleh Afandi (2018) yang menyatakan bahwa penggunaan media tutup botol bekas minuman dalam proses pembelajaran mampu mendorong peningkatan kemampuan membilang pada anak TK. Penggunaan media tutup botol bekas minuman tersebut mampu menarik minat anak untuk belajar secara menyenangkan, sekaligus membantu anak dalam melakukan penghitungan, yaitu dengan cara meletakkan tutup botol bekas minuman satu per satu ke dalam mangkok plastik sambil menghitungnya. Anak merasa sedang melakukan suatu permainan karena media belajar yang digunakan terbuat dari tutup botol bekas. Hal ini yang menjadikan media belajar dari barang bekas dapat secara efektif mendorong kemampuan membilang anak.

Morisson mengemukakan mengenai kecerdasan matematika anak, dimana ketika anak-anak mampu memperlihatkan bakat di bidang angka, penalaran, dan penyelesaian masalah. Anak-anak yang memiliki kecerdasan logika matematika biasanya menyukai permainan dengan menggunakan angka atau sesuatu yang membutuhkan daya nalar (Suripatty dan Nurani, 2020). Berhitung dan kardinalitas merupakan bagian dari bidang matematika yang perlu dimiliki oleh anak sebagai wujud dari perkembangan kognitifnya. 
Hal tersebut selaras dengan yang dikemukakan oleh (Nasution dan Maulana, 2020) bahwa berhitung termasuk kedalam salah satu aspek perkembangan kognitif yang harus dikembangkan oleh guru, karna berhitung dibutuhkan anak dalam kehidupan sehari-hari, terutama konsep bilangan yang merupakan dasar untuk mengembangkan kemampuan matematika maupun kesiapan untuk mengikuti pendidikan dasar.

Selain memiliki manfaat dalam meningkatkan kemampuan berhitung dan kardinalitas penggunaan media belajar rangkasbitung juga memiliki beragam manfaat lain, seperti proses pembuatannya yang mudah dan tidak membutuhkan banyak biaya; menjadi media pembelajaran yang tidak hanya mengajarkan kepada anak masalah perhitungan, namun juga mengajarkan pentingnya mengurangi, menggunakan kembali, dan mendaur ulang sampah-sampah; dan memberikan kesempatan luas bagi guru untuk mengembangkan kreativitasnya dalam menciptakan media pembelajaran yang paling sesuai dengan kebutuhan siswanya. Selain itu, tampilan media pembelajaran rangkasbitung cenderung sangat disukai oleh anak-anak, sehingga dapat membangkitkan minat dan motivasi belajar tinggi (Sudarwati, 2018). Hasil penelitian yang di kemukakan di atas memberikan implikasi bahwa keaktifan peserta didik dalam memanipulasi media mampu memberikan dorongan untuk membangun pengetahuan dalam hal ini kemampuan berhitung dan kardinalitas melalui media rangkasbitung.

Jika ditinjau dari sudut pandang perkembangan anak menurut konsep yang dikemukakan oleh Santrock (2014), maka media pembelajaran rangkasbitung memiliki kesesuaian untuk digunakan dalam kegiatan belajar pada siswa seusia TK karena media tersebut mampu memperkuat pemikiran simbolis dari anak untuk mewakili persepsinya. Dalam hal ini, siswa memiliki ketertarikan terhadap bentuk dari berbagai alat dan bahan main dalam media rangkasbitung, sehingga siswa dapat menerima penggunaan media belajar tersebut dengan baik.

Melalui media siswa dapat lebih memperhatikan terhadap benda-benda atau hal-hal yang belum pernah dilihatnya yang berkaitan dengan pelajaran. Sehingga pengalaman dan pengetahuan siswa menjadi lebih luas, lebih jelas dan tidak mudah dilupakan, serta lebih konkret dalam ingatan dan asosiasi peserta didik (Zuhdi dan Ulhaq, 2014).

Berdasarkan hasil analisis dan temuan data yang telah tersaji, menunjukkan bahwa kemampuan berhitung dan kardinalitas anak mengalami peningkatan. Selain itu proses belajar mengajar menjadi lebih aktif dan menyenangkan serta menumbuhkan rasa cinta lingkungan dengan sadar dalam pemanfaatan barang bekas di sekitar anak.

\section{SIMPULAN}

Aktivitas siswa kelompok B TKIT Al Faruqi mengalami peningkatan setelah penerapan kegiatan belajar menggunakan media rangkasbitung. Peningkatan tersebut terjadi secara signifikan, yaitu dari skor rata-rata aktivitas siswa sebesar 12,5 dengan kategori kurang meningkat menjadi 25,5 dengan kategori baik. Melalui penerapan media rangkasbitung yang lebih fleksibel, yaitu dengan cara memberikan prioritas perhatian guru kepada siswa yang kurang aktif untuk didorong hingga menjadi semakin aktif berpartisipasi dalam kegiatan belajar. Media rangkasbitung memiliki tampilan yang menarik, sehingga mampu membuat siswa merasa senang dan termotivasi untuk aktif berpartisipasi dalam proses pembelajaran. Penggunaan media belajar rangkasbitung terbukti mampu meningkatkan kemampuan berhitung dan kardinalitas siswa kelompok B TKIT Al Faruqi. Hal ini terlihat dari adanya peningkatan dalam skor rata-rata kemampuan berhitung dan kardinalitas siswa antara pra-siklus, siklus 1, hingga siklus 3. Hal ini disebabkan karena media belajar rangkasbitung mampu mensederhanakan konsep berhitung dan mempraktikkannya dengan alat-alat dan bahan yang familiar. Konsep-konsep yang dinilai abstrak dalam berhitung dan kardinalitas bagi anak menjadi mudah dipahami dan disederhanakan dengan penggunaan media rangkasbitung. 


\section{UCAPAN TERIMAKASIH}

Terima kasih kepada dosen pembimbing, yang telah mendampingi menyempurnakan hasil penelitian ini. Khususnya kepada kedua orangtua dan seluruh keluarga yang mendukung dan selalu menjadi penyemangat hingga terselesaikannya penelitian ini.

\section{DAFTAR PUSTAKA}

Afandi, A. (2018). Pengaruh Media Tutup Botol Bekas Minuman terhadap Kemampuan Membilang. Jurnal AUDI, 3(2), 80-85. https://doi.org/10.33061/ad.v3i2.2728

Boggan, M., Harper, S., \& Whitmire, A. (2010). Using manipulatives to teach elementary mathematics. Journal of Instructional Pedagogies, 3(1), 1-10.

Cotet, G. B., Balgiu, B. A., \& Zaleschi (Negrea), V. - C. (2017). Assessment procedure for the soft skills requested by Industry 4.0. MATEC Web of Conferences, 121(2), 07005. https:// doi.org/10.1051/matecconf/201712107005

Ismayani, A. (2010). Fun Math With Children: Mengenalkan Matematika Kepada Anak Usia 2 Hingga 6 Tahun Melalui Beragam Aktivitas. Jakarta: Elex Media Komputindo.

John W. Santrock. (2014). Adolescence fifteenth edition. Dallas: University of Texas.

Muslihuddin. (2014). Kita Sukses Melakukan Penelitian Tindakan Kelas E Sekolah (M. P. Dr. H Mubiar Agustin, ed.). Bandung: Rizqi Press.

Nasution, N., \& Maulana, I. (2020). Jurnal Obsesi : Jurnal Pendidikan Anak Usia Dini Analisis Pembelajaran Berhitung melalui Media Prisma Pintar pada Anak Usia Dini Abstrak. 4(1), 230236. https://doi.org/10.31004/obsesi.v4i1.311

Pixner, S., Dresen, V., \& Moeller, K. (2018). Differential development of children's understanding of the cardinality of small numbers and zero. Frontiers in Psychology, 9(SEP), 1-11. https:// doi.org/10.3389/ fpsyg.2018.01636

Rosita, Fadillah, D. (2013). Pengembangan Potensi Kognitif Anak Melalui Bermain Konstruksi dengan Lego di TK. KARTIKA V-49 Pontianak.

Sa'diyah, S., \& Zuhdi, U. (2014). Pemanfaatan Media Gambar untuk Meningkatkan Hasil Belajar pada Tema Diri Sendiri Siswa Kelas II SD Islam Plus Al-Azhar Mojokerto. Jurnal Penelitian Pendidikan Guru Sekolah Dasar (JPGSD), 3(2), 1-10.

Setiawan, D. (2015). Penelitian Tindakan Kelas, Apa Mengapa dan Bagaimana. Jakarta: PT Semesta Rakyat Merdeka RM BOOKS.

Siarni, Pasaribu, M., \& Arman. (2015). Pemanfaatan Barang Bekas Sebagai Media Pembelajaran Untuk Meningkatkan Hasil Belajar IPA Siswa Kelas IV SDN 07 Salule Mamuju Utara. Jurnal Kreatif Tadulako, 3(2), 94-104. https:/ / doi.org/ISSN 2354-614X

Sudarwati, U.-. (2018). Peningkatan Kemampuan Membilang 1 - 20 melalui Permainan Puzzle pada Anak Kelompok B di TK Tunas Rimba 1 Samarinda Tahun Pembelajaran 2016/2017. Jurnal Warna : Pendidikan Dan Pembelajaran Anak Usia Dini, 3(1), 20-37. https:// doi.org/10.24903/jw.v3i1.206

Sugiyono. (2008). Metode Penelitian Pendidikan. Bandung: CV. Alfabeta.

Suripatty, P. J. P., \& Nurani, Y. (2020). Jurnal Obsesi : Jurnal Pendidikan Anak Usia Dini Peningkatan Kecerdasan Logika Matematika melalui Permainan Bingo Abstrak. 4(1), 100-109. https:// doi.org/10.31004/obsesi.v4i1.282

Yuliani, N. (2019). Perspektif Baru Konsep Dasar Pendidikan Anak Usia Dini. Jakarta: PT. Indeks. 